\title{
Dos hermanos muy distintos. El caso chileno y argentino en perspectiva comparada.
}

\author{
Two very different brothers: a comparison of the \\ Chile and Argentina cases.
}

\section{Pedro Aravena Lavín*}

\section{Resumen}

Pese a las fuertes crisis ecnómicas de las última décadas,Argentina cuenta con uno de las mayores niveles de apoyo a la democracia en América Latina; en Chile, pese a que es uno de los países de mayor éxito económico en la región, el apoyo a la democracia es mediocre. Este artículo presenta una comparación entre análisis de regresión logística ordenada para los años 1997 y 2001. Los modelos se complementan respecto de la cultura política de ambos casos. La estabilidad económica, la distribución del ingreso, la confianza interpersonal, el interés en la política y la educación cívica son factores más significativos en el caso argentino que en el chileno. Al momento de apoyar la democracia, en Chile se observa una fuerte polarización de la orientación política de izquierda y derecha.

Palabras Clave: Apoyo a la democracia, perspectiva comparada, cultura política, Chile, Argentina

* Doctorando, GIGA Hamburgo, aravena.pedro@gmail.com

Recibido el 10 de julio de 2012; aceptado el 14 de septiembre de 2012 


\section{Abstract}

Argentina has one of the highest standards of support for democracy in Latin America despite the economic crises of recent decades while Chile, despite being one of the most economically successful countries in the region, has a poor support for democracy. This article presents a comparison of ordered logistic regression analysis of the year 1997 with the year 2001. In addition, such models are complemented with respect to the political culture in both countries. Economic stability, income distribution, interpersonal trust, interest in politics and civic education are more significant factors in the Argentinean than in the Chilean case. There is a strong polarisation between the political orientation of left and right in Chile with regard to the support of democracy.

KEYWORDS: Support for democracy, comparative perspective, political culture, Chile, Argentina. 


\section{INTRODUCCIÓN}

El apoyo a la democracia ha sido fuertemente estudiado en la ciencia política. Es abundante la literatura que señala los factores condicionantes de este. Es decir, es fuerte la discusión acerca de los factores que mayormente impactan tal apoyo. Por ejemplo, Cutright (1963), Lipset, Seong y Torres (1993), Huntington (1991) y Diamond (1992) argumentan que son las variables socioeconómicas, tales como PIB per cápita, educación, pobreza, urbanización, etc., las que proporcionan un mayor apoyo al sistema democrático. Lerner (1958), Lipset (1959), Deutsch (1961), Huntington (1984) y Klingemann y Fuchs (1998) culpan a los indicadores macroeconómicos, tales como inflación, desempleo, PIB, etc. Por otro lado, Mainwaring (1993), Lijphart (1977), Linz y Valenzuela (1994) y O`Donnell (1973) señalan que el apoyo al sistema democrático guarda más relación con factores políticos tales como liderazgo político, teoría de la democracia consensual y parlamentarismo frente al presidencialismo, mientras que Fuchs, Guidorossi y Svenson (1995), Berggren (2004) y Anderson y Guillory (1997) aluden que se relacionan con factores institucionales, tales como la representatividad y los sistema de partidos. Gasiorowski (1988; 1995), considerando una perspectiva distinta, estudia el impacto de los factores internacionales como la dependencia económica y las relaciones de interdependencia. Almond y Verba (1965), Inglehart (1991), Hu- neeus y Maldonado (2003), Weil (2000) y Putnam (1995) se refieren al impacto de los factores culturales, es decir, históricos con base en características del sistema político, sus procedimientos, diversos aspectos de la vida económica al igual que características religiosas y conforme a la tematica del capital social. La escuela de Michigan, asociada a Converse (1969) y Knuston (1973), entre otros, hace referencia a la psicología política, mientras que Swanson (1995) y Sartori (1999) se refieren a la democracia mediática o mediocracia como elementos de importancia en el apoyo al sistema democrático.

Por añadidura, el apoyo a la democracia corresponde a una medida de legitimidad de la democracia. Donde este último concepto hace referencia al convencimiento de la población de que la democracia es la menos mala de las formas de gobierno, independientemente de la opinión que tengan respecto del desempeño del gobierno en decisiones concretas (Linz 1988: 65). Ciertamente, el centro de encuestas Latinobarómetro operacionaliza tal legitimidad, con el objetivo de ser mensurable, de manera que formula una pregunta para dar conocer si el encuestado prefiere un régimen político democrático, uno autoritario o si le es indiferente ${ }^{1}$.

1 Con cuál de las siguientes frases está Ud. más de acuerdo? (1) La democracia es preferible a cualquier otra forma de gobierno, (2) En algunas circunstancias, un gobierno autoritario puede ser preferible a uno democrático, (3) A la gente como uno, nos da lo mismo un régimen 
Los acontecimientos económicos, como factores que impactan el apoyo a la democracia, también han sido objeto de estudios y diversos supuestos. Por ejemplo, las crisis económicas. Acemoglu y Robinson (2006: 65) señalan que dentro de la teoría de la democratización las crisis económicas corresponden a uno de los elementos de mayor importancia. Aquello puesto que la evidencia histórica nos demuestra que es posible esperar una fuerte relación entre una severa crisis y la transición a la democracia.

La presente investigación, haciendo alusión al apoyo a la democracia como variable dependiente, se basa en un estudio comparativo entre Chile y Argentina considerando dos períodos de estudio: crecimiento económico y crisis económica.

Ahora bien, la problemática al estudiar ambos casos en perspectiva comparada es la siguiente: «Según el Anuario Estadístico de la Comisión Económica para América Latina y el Caribe (2003) y el informe Latinobarómetro (2003), Argentina, pese a ser uno de los países que ha sido más afectado por una crisis económica cuenta con unos de los más altos niveles de apoyo a la democracia en Latinoamérica. No obstante, Chile aunque es uno de los países más exitosos en materia económica en la región $\mathrm{y}$ a haber sido menos afectado por crisis económicas cuenta con un nivel moderado de apoyo a la democracia».

democrático que uno no democrático, $(8)$ No sabe, (0)
Desde esta perspectiva, se infiere que en la temática política y económica múltiples factores

pudieron influir en los actuales niveles de percepción sobre la democracia en estos casos. Primero, se perciben diferencias en la manera en que desarrollaron sus políticas económicas. Es decir, a partir de 1973 Chile establece un modelo de economía de mercado y liberalización comercial que permanece virtualmente intacto hasta hoy, mientras en Argentina, el modelo implantado - por así decirlo - gradualmente a partir de 1973 se ve interrumpido en 1976 por el gobierno de facto de Jorge Rafael Videla, continuando este hasta el término del mandato del presidente Raúl Alfonsín. Los gobiernos de facto que luego se prolongaron, así como el gobierno democrático de Alfonsín, optaron por un modelo de sustitución de importaciones orientado a ordenar el sistema económico instaurado por el populismo macroeconómico. Segundo, desde la época de la dictadura el pueblo argentino ha tenido más poder de crítica frente al sistema político que el caso chileno; además, existieron particularidades en ambos regímenes militares que forjaron la diferencia en la apreciación por parte de la población de un sistema autoritario. El movimiento obrero argentino, a diferencia del caso chileno, opuso gran resistencia a la dictadura y cuestionó de hecho toda legitimidad del sistema político autoritario (Abós 1984). El gobierno militar, buscando algún consenso para superar el desgaste agregado en varios años de gestión im- 
popular, y enfrentado plenamente a la crisis económica que se haría dramática en 1982, intentó convocar la unidad nacional en pos de la recuperación de las Islas Malvinas de manos de Gran Bretaña, pero tras el fracaso de la guerra, el gobierno militar, con el general Galtieri a la cabeza, se vio obligado a llamar a elecciones libres. Por otro lado, todo tipo de manifestaciones contra el régimen de Augusto Pinochet fueron duramente reprimidas, implantándose una sangrienta y larga dictadura (Sepúlveda 2006).

Por todo lo anteriormente descrito, mediante una regresión logit ordenado para los mismos años de estudio y a través del testeo de las mismas variables independientes se busca explicar, desde una perspectiva comparada, qué variables son mayormente significativas para el apoyo a la democracia en un período de crecimiento económico y en uno de crisis económica. Los resultados de tal metodología serán complementados por una breve indagación de los traumas políticos y económicos ocasionados por los regímenes de facto, puesto que se infiere que han tenido evidente influencia en los actuales niveles de apoyo a la democracia.

\section{Pregunta de investigación E HIPÓTESIS}

La pregunta de investigación que se plantea es la siguiente:

¿Por qué hay mayor apoyo a la democracia en Argentina que en Chile?
En relación a esta pregunta, la hipótesis que se prueba es la siguiente:

Los traumas políticos heredados por los regímenes autoritarios han hecho que el apoyo a la democracia en Argentina sea mayor al de Chile.

\section{Metodología}

La presente investigación utiliza el método comparado entre Chile y Argentina. Aquí se miden los mismos factores de análisis durante los mismos períodos de tiempo a fin de dar a conocer cómo se diferencian tales casos de estudio. Este método nos proporciona una base para poder llegar a afirmaciones sintetizando elementos diferenciadores y comunes relativos a un fenómeno en particular (Caïs, 1997). Ciertamente, tal comparación nos proveerá de elementos constitutivos de una identidad propia. Como argumenta Sartori (1994), es posible conocer la propia nación al definir primeramente otra. Esa es la principal indagación de esta investigación, es decir, dar a conocer cómo Chile y Argentina, países vecinos, pese a compartir elementos culturales similares, en términos de cultura política se muestran muy distintos.

Con respecto a la metodología estadística se realizan cuatro modelos, para los años 1997 y 2001, en Argentina y Chile. El objetivo del testeo de ambos años es analizar el comportamiento de la variable endógena en un año de crecimiento económico en contraste con uno de crisis. Las estimaciones son a nivel 
individual y fueron realizadas mediante una metodología de datos ordenados denominada logit ordenado.

Según los modelos presentados, las variables independientes utilizadas se clasifican en económicas, socioeconómicas, institucionales y políticas. En consecuencia, es posible esperar que la variable endógena dependa de estas de la siguiente manera:

Apoyo a la democracia $=$ F (Per cepción de la estabilidad económica, Distribución del ingreso, Educación, Corrupción, Confianza interpersonal, Confianza en los partidos políticos, Confianza en el parlamento, Confianza en el poder judicial, Escala política (izquierda), Escala política (derecha), Escala política (centro), Interés en la política)

En los modelos logit presentados la variable endógena se interpreta en términos de probabilidad por lo que el objetivo del estudio es cuantificar la relación existente entre las características individuales de los encuestados con esa probabilidad. Los coeficientes de regresión estimados que se obtendrán estiman las ventajas relativas de cada una de las variables categóricas del modelo. Por consiguiente, esto permitirá dar a conocer cuál de estas variables tiene mayor valor explicativo respecto del apoyo a la democracia desde una perspectiva individual.

Si bien el modelo logit es un tipo especifico de regresión y se caracteriza por una variable endógena dicotómica, mientras que las variables explicativas pueden ser categóricas o continuas, la estimación logit ordenado permite ordenar las alternativas de la variable endógena de manera que representen un orden entre ellas. En consecuencia, esta variable puede tomar valores, tales como: 1,0 y -1 , los cuales corresponden a alternativas que expresan si el encuestado apoya, se siente indiferente o no apoya la democracia.

Los modelos estadísticos buscan medir el mismo fenómeno en perspectiva comparada, es decir, el impacto de las crisis económicas en el apoyo a la democracia. Esto, puesto que se parte del supuesto de que las crisis económicas pueden causar efectos en los niveles de apoyo a la democracia y en consecuencia son acontecimientos o sucesos que deben ser explorados. Según el Anuario Estadístico de la Comisión Económica para América Latina y el Caribe (2004), Chile sufrió la crisis asiática con una caída en el PIB per cápita a partir del año 1998, alcanzando la mayor baja en el año 1999, con un crecimiento negativo de $-1,4 \%$. Por otro lado, Argentina sufrió la crisis asiática, la crisis cambiaria rusa y la crisis brasileña, detonando la crisis económica del año 2001 en que el PIB per cápita cayó hasta $1-11,7 \%$ durante el año 2002. Si bien el impacto de las crisis económicas fue diferente en ambos países, se registró un fuerte deterioro del PIB per cápita, por lo que se considera que el año 2001 fue un período de crisis económica. 
Pedro Aravena Lavín • Dos hermanos muy distintos

Gráfico 1: Crecimiento del PIB per cápita en Chile y Argentina en perspectiva comparada (porcentajes)

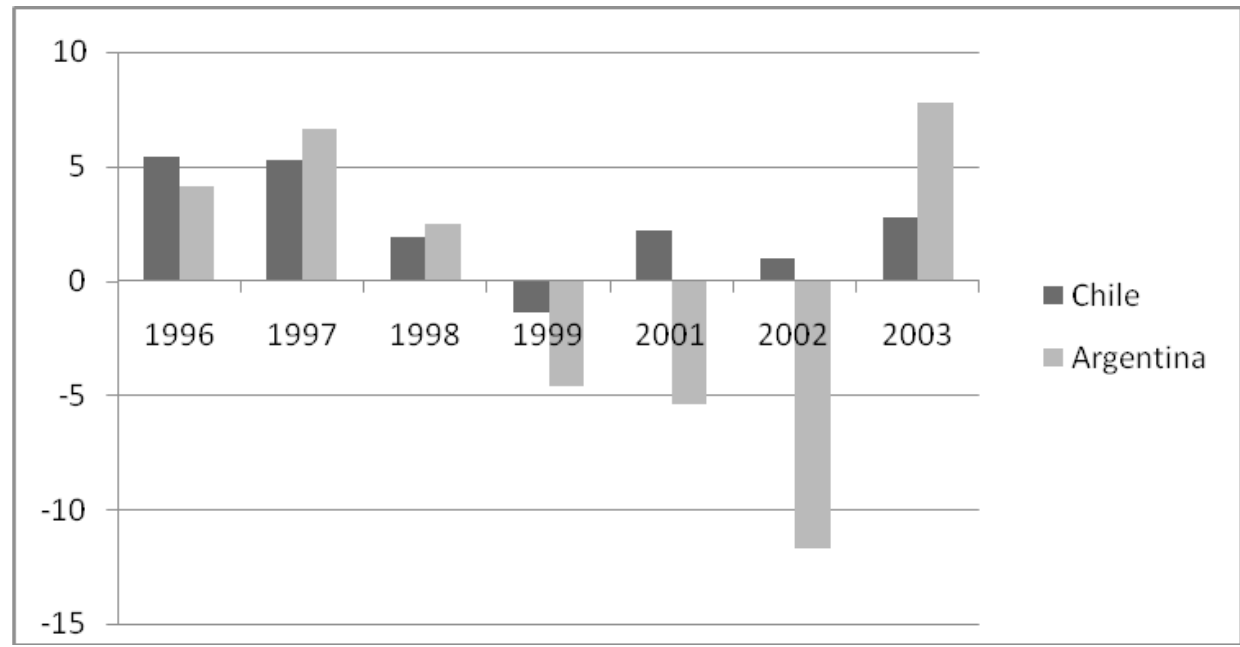

Fuente: Elaboración propia a partir de datos proporcionados por los anuarios estadísticos de la Comisión Económica para América Latina y el Caribe (CEPAL)

Se utiliza el modelo «logit ordenado" puesto que según las características de la variable dependiente «apoyo a la democracia» la literatura ad hoc nos recomienda seleccionar los modelos de elección discreta. Es decir, se pudo haber optado por otras especificaciones, pero el análisis se limitó a los modelos logit ordenados debido a que las alternativas de la variable endógena representan un orden entre ellas 2 . Entonces, las preguntas acerca del apoyo a la democracia proporcionan alternativas de carácter ordinal:

$$
\begin{aligned}
& \mathrm{Yi}=1 \text { if } Y_{i}^{*} \text { is } \leq \kappa 1 \\
& \mathrm{Yi}=0 \text { if } \kappa 1 \leq Y_{i}^{*} \leq \kappa 2 \\
& \mathrm{Yi}=-1 \text { id } Y_{i}^{*} \geq \kappa 2
\end{aligned}
$$

2 Huang, Chang y Chu, 2008; Graham y Sukhtankar, 2004.
Es decir ${ }^{3}$,

1 si ocurre el acontecimiento objeto de estudio, es decir, si $Y_{i}^{*}$ es menor o igual a $\kappa 1$

$Y_{i}=0$ si hay indiferencia, es decir, si c1 es menor o igual a $Y_{i}^{*}$ y éste es menor o igual a $\kappa 2$

-1 si ocurre el caso contrario, es decir, si k2es menor o igual a $Y_{i}^{*}$

El programa utilizado es el STATA versión 9, el comando es «ologit» y la operacionalización de las variables se encuentran en el anexo ${ }^{4}$. La ecuación del modelo es el siguiente:

3 Ver la pregunta para medir el apoyo a la democracia en el anexo.

4 Para mayor profundización en la utilización de análisis econométricos por medio 


$$
Y_{i}^{*}=\mathrm{a}+\mathrm{BX}_{\mathrm{i}}+\mathrm{e}_{\mathrm{i}}
$$

Para estimar la variable observable se considera la variable latente (no observable) « $Y_{i}^{*} »$ equivalente a la probabilidad de que se produzcan los valores 1, 0 o -1. Esta variable va a depender linealmente de la variable explicativa «BX $\mathrm{B}_{\mathrm{i}}$. «X» es el vector de las variables independientes; «B» es el vector de los coeficientes de regresión que deseamos estimar; «i» corresponde al atributo i-ésimo y « $e_{i}$ » es el término de error del modelo.

\section{Resultados}

Los resultados de la metodología propuesta, desde una perspectiva comparada, permiten distinguir cuatro agrupaciones de factores de interés: el impacto económico en el apoyo al sistema democrático, de la confianza interpersonal, del nivel de educación y de la orientación política.

\section{El impacto económico}

Chile y Argentina pasaron por regímenes militares con características distintas. Ciertamente, una de las grandes diferencias fue respecto de las variantes en los modelos de mercado. El gobierno de Chile, con Pinochet a la cabeza, instauró un modelo neoliberal con total facultad de aplicar las políticas

de STATA se recomienda ver Hamilton, 2006. que se deseasen. Se eliminó el control de precios; se redujeron dramáticamente los aranceles, incentivando las importaciones; se liberalizaron los mercados financieros y los flujos de capital internacional, se reestructuró y redujo el sector público, se revirtió la reforma agraria y se inició un agresivo proceso de privatización de empresas públicas (Davis y Labán 1996). En 1980, quedaron únicamente 43 empresas sin privatizar de las 500 empresas estatales que existían en la época de Allende 5 .

Por otro lado, Argentina pasó del modelo de sustitución de importaciones a la ortodoxia y economía de mercado tardíamente, en 1990. Además, es ampliamente reconocido como el mayor problema económico que no haya logrado consolidar un modelo que le permita crecer a tasas competitivas.

Argentina se ha caracterizado por permanentes períodos inflacionarios de 1972 en adelante. En ese año la inflación cerró en un $64 \%$. Después del gobierno populista de Juan e Isabel Perón la inflación bordeó un 350\% anual. El excesivo gasto fiscal durante la Guerra de las Malvinas, contribuyó a que en 1983 la inflación se aproximara al 430\%. En 1989, durante el gobierno de Raúl Alfonsín, la inflación llegó a un record histórico de $4923 \%$. Carlos Saúl Ménem asume el gobierno en una compleja situación económica y en 1990 la inflación se sitúa en un $1343 \%$.

Luego de décadas de estancamiento económico renace la figura de Domingo

\footnotetext{
Davis y Labán (1996) op cit.
} 
Cavallo, economista de corte liberal, por entonces Ministro de Relaciones Exteriores. Fue el impulsor de la ley de convertibilidad que igualaba el peso argentino con el dólar estadounidense. Al comienzo esta medida resultó ser un éxito y se logró controlar la hiperinflación e impulsar el crecimiento de de crecimiento económico negativo, mientras que en Chile solo tres (en la crisis de 1982 y en la crisis asiática). Entre 1976 y 2005 el valor medio del crecimiento económico en Argentina fue de 1,98\%, en Chile de 5,41\% ${ }^{6}$.

Por todo lo anterior, no resulta extraño que según los resulta-

Gráfico 2: Análisis histórico del crecimiento del PIB per cápita en Chile y Argentina en perspectiva comparada (porcentajes)

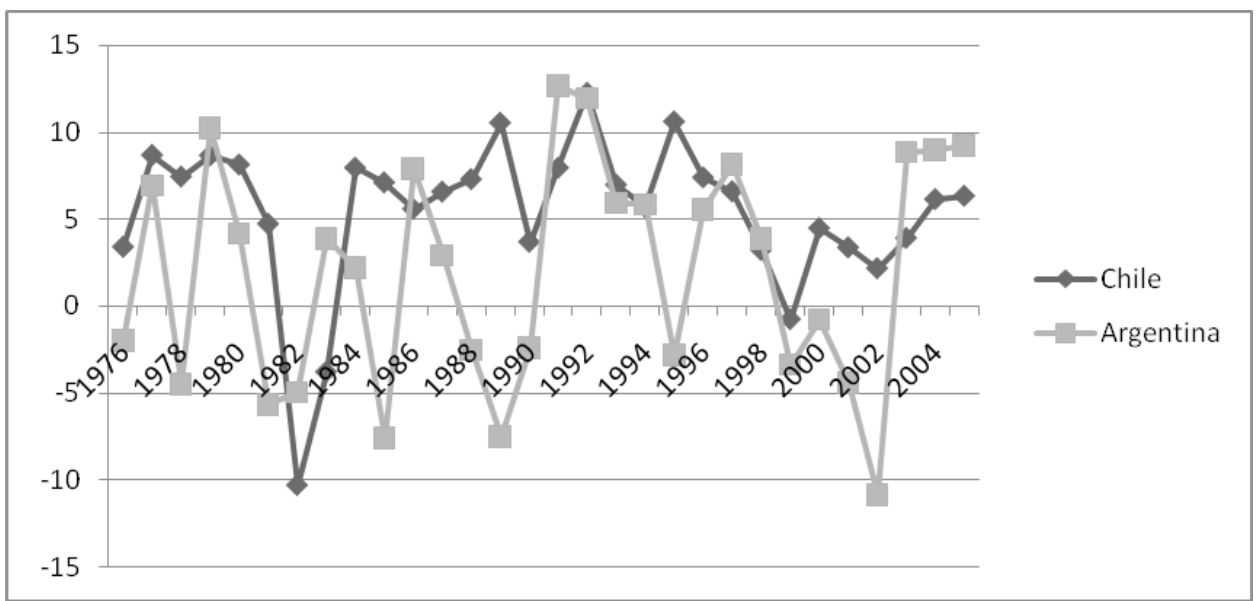

Fuente: Elaboración propia a partir de datos proporcionados por DataGov (Governance Indicators Database).

la economía durante los años noventa. No obstante, en 2001 terminó por ser una de las causantes de una de las peores crisis financieras de la historia de Argentina.

Al comparar el caso chileno con el argentino, como puede apreciarse en el siguiente gráfico, se comprueba que en los decenios pasados el segundo ha sufrido muchos más períodos de crisis económica. Desde 1976 a 2005 en Argentina se han producido 13 años dos de esta investigación, hay una tendencia que indica que Argentina atribuye más importancia que Chile a la estabilidad de la economía como factor condicionante del apoyo a la democracia. Ciertamente, durante 1997 la variable "percepción de la estabilidad económica» tuvo un correlato estimado y significativo de $-0,7027$ y $-0,3743$ para el caso argentino y chileno, re-

6 DataGov: http://www.iadb.org/DataGob/ 
spectivamente. Durante el año 2001, el correlato estimado solo fue significativo para el caso argentino, con un valor de $-0,4510$ al $5 \%$.

\section{El impacto de la confianza interpersonal}

La confianza interpersonal es una variable que ha sido estudiada ampliamente por diversas ramas científicas, siendo una de las más importantes la sicología. Petermann (1999) entiende tal confianza desde tres perspectivas: personalidad, situación y relación. La primera consiste en la clasificación de las personas como confiadas o desconfiadas. En lo que respecta a la variable situacional, el autor hace referencia a las «variables de refuerzo y entorno". Desde esta perspectiva, se distinguen diferencias según el género, las variables neutrales de poder y el tipo de informaciones que se generan. Aquí quedan excluidas las diferencias que pudiesen existir entre la población del campo o ciudad, y la relación entre la confianza y el stress, puesto que no hay estudios que las confirmen. La variable relación se aproxima más a un término sociológico y se refiere a una propuesta para reducir el riesgo. En esta perspectiva, se ha estudiado el «dilema del prisionero», que corresponde a un test o problema fundamental de la «teoría de juegos». ${ }^{7}$

Considerando exclusivamente el área de la ciencia política, la confianza interpersonal desempeña un papel relevante

\footnotetext{
Petermann (1999) op cit.
}

dentro del debate sobre el capital social (Almond y Verba 1963), la cultura política (Putnam 1994) y las redes sociales (Burt 2000). En consecuencia, a partir de la confianza interpersonal se ha intentado estudiar la confianza en las instituciones, partiendo del supuesto de que esta se explica a través de la primera. Estudios de casos han demostrado que la confianza interpersonal influye en la institucional, como ha sucedido en los Estados Unidos (Levi 1998; Putnam 1993).

En consecuencia, según los teóricos que defienden la tesis de orden culturalista, que señala que la confianza se relaciona con las normas transferidas hacia los individuos en el proceso de la socialización, la confianza en las instituciones es una extensión de la confianza interpersonal, aprendida tempranamente en la vida, y más tarde proyectada en la confianza en las instituciones (González 2006).

Al respecto, Putnam (1994) sugiere que la confianza interpersonal juega un importante rol en ámbitos sociales en general. Una sociedad rica en confianza interpersonal, redes sociales y organizaciones de acciones voluntarias tiene mayores probabilidades de crear instituciones políticas eficaces y mejorar los resultados económicos. Es decir, una sociedad civil activa impone controles sociales a las instituciones políticas y económicas, generando un aumento de la rendición de cuentas y de la productividad.

Ahora bien, en cuanto a los datos logrados a través de los modelos estadísticos presentados en el anexo se 
percibe una tendencia que indica que en Argentina el apoyo a la democracia está fuertemente influenciado por el nivel de confianza interpersonal, no así el caso chileno. Además, como se muestra en el siguiente gráfico, Argentina generalmente ha contado con un mayor nivel de confianza interpersonal que Chile, donde únicamente supero este último en los años 1999 y 2001, lo que hace distinguir el impacto de las crisis económicas en tal variable.
Ahora bien, ¿por qué la confianza interpersonal juega un rol de importancia respecto del apoyo a la democracia en Argentina pero no en Chile?. Desde una perspectiva sicológica, la confianza interpersonal es inversamente proporcional a la incertidumbre social, es decir, al riesgo de ser explotado en interacciones sociales. En consecuencia, a mayor incertidumbre social, mayor temor a que se establezcan relaciones fuertes y duraderas (Páez y Campos 2004). Estos

\section{Grafico 3: Confianza interpersonal (porcentajes)}

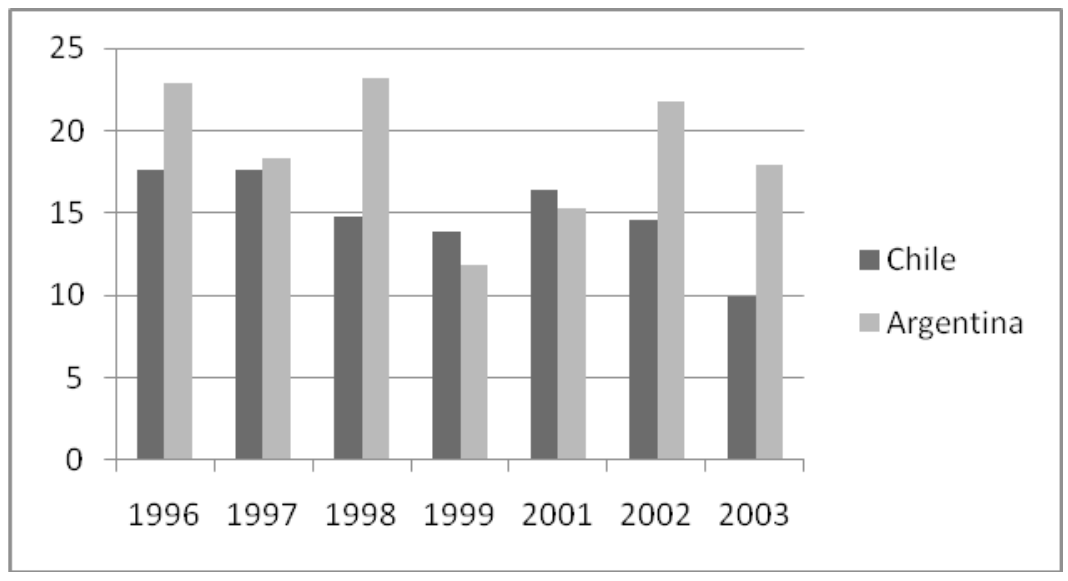

Fuente: Elaboración propia a partir de datos de Latinobarómetro.

Por lo tanto, puede inferirse que el elevado apoyo a la democracia en Argentina, comparado con el de Chile, se relaciona fuertemente con el alto nivel de confianza interpersonal y, en consecuencia, es también uno de los factores causantes de que las crisis económicas influyeran en el apoyo a la democracia en Argentina . argumentos están fuertemente conectados con términos políticos. Existen investigaciones basadas en análisis de regresiones estadísticas que sugieren que los niveles de confianza interpersonal se relacionan con la corrupción y la estabilidad política. Jong-Sung You (2005),mediante un modelo jerárquico no-lineal de dos niveles y utilizando la base de datos del World Values Survey y 
European Values Study para 80 países, concluye que la equidad de una sociedad afecta la confianza interpersonal. Es decir, las sociedades más justas en materia de procedimientos democráticos y respecto de la administración equitativa de las normas, con menores niveles de corrupción y una distribución equitativa del ingreso, aumenta tal grado de confianza.

De lo anterior puede deducirse que la importancia de la corrupción y el desarrollo del sistema político, económico y social argentino hace que la confianza interpersonal cumpla una función predominante para el sistema democrático. En otras palabras, son factores especialmente sensibles para el caso argentino, que permitirían producir una mayor confianza interpersonal y, a su vez, son importantes para el devenir democrático.

\section{El impacto de la educación y el interés en la política}

En lo que toca a la importancia de la educación para la democracia existen extensos artículos para el caso de América Latina. Por ejemplo, utilizando modelos sucesivos de OLS (Ordinary least squares) Carlin (2006) examinó cómo el contexto y el estado socioeconómico afectan el apoyo a la democracia en América Latina. Su estudio se basó en el testeo de 8 países latinoamericanos durante distintos períodos, desde el año 1995 al año 2000, por medio de la base de datos World Values Survey, concluyendo que en América Latina la educación tiene importancia significativa en el apoyo a la democracia. Esta variable dio el coeficiente de correlación más importante del modelo frente a otras, tales como el PIB per cápita, la desigualdad, la pobreza, la inflación, el desempleo y el ingreso. Igualmente, Graham y Sukhtankar (2004) examinaron la influencia de la educación en el apoyo a la democracia durante la crisis económica del año 2001 en América Latina. Los autores realizaron una estimación Logit Ordenado utilizando variables, a nivel individual, del centro de encuestas Latinobarómetro, concluyendo que esta variable tiene una correlación positiva y significativa. Por su parte, Carlos Huneeus (2003), al examinar el apoyo a la democracia en el caso chileno durante el año 2001 mediante una regresión logística a nivel individual con los estadísticos de Cox-Snell y de Nagelkerke, y utilizando la base de datos de Latinobarómetro, comprobó que la variable educación tiene el coeficiente de regresión positivo y significativo más alto del modelo, es decir, los entrevistados con estudios universitarios apoyan más la democracia que aquellos con un nivel inferior de educación.

Según los resultados de esta investigación, en Argentina la variable educación es positiva y consistente. Es decir, aquellos que más apoyan la democracia son aquellos que también cuentan con estudios superiores ya sea en la Universidad o Instituto ${ }^{8}$. Tal variable tiene un fuerte trasfondo en relación con el creci-

8 Ver la construcción de las variables en el anexo. 
miento económico puesto que al aumentar este aumentan las posibilidades de lograr una mayor educación. También, es sabido que se vincula con una serie de factores socioeconómicos, como el nivel de ingreso, la desigualdad y la pobreza. Desde esta perspectiva, certeras son las palabras de Ocampo (2003) cuando se refiere a la educación como el factor clave para el fortalecimiento de la democracia: «El panorama actual de la región muestra que el acceso a una educación de calidad sigue estando muy segmentado. La educación presenta grandes brechas en materia de logros y retornos según el nivel de ingreso y localización territorial, con lo que se reproducen las inequidades en las futuras trayectorias laborales y familiares».

Ahora bien, al comparar los resultados del caso argentino con el chileno se concluye que la precaria enseñanza sobre la democracia que se observa en los niveles educacionales de Chile hace que la variable «educación» no sea trascendente para el apoyo a la democracia. Es decir, en la educación urge aplicar la cultura cívica y los valores democráticos.

Según las entrevistas LAPOP (2008), la población chilena tiene un precario conocimiento político ${ }^{9}$. Por medio del

$9 \quad$ El índice de conocimiento político se mide mediante las siguientes preguntas: GI1. ¿Cuál es el nombre del actual presidente de los Estados Unidos? GI2. ¿Cómo se llama el Presidente del Congreso/Asamblea de su país? GI3. ¿Cuántas provincias/ departamentos/estados tiene el país? GI4. ¿Cuánto tiempo dura el período presidencial en el país? GI5. ¿Cómo se llama el índice de conocimiento político creado a partir de una serie de preguntas que miden qué tan informada se encuentra la población de un determinado país, Chile tiene una puntuación de 51,1 mientras que la de Argentina es de 67,4. La puntuación máxima es obtenida por Uruguay $(70,1)$ mientras que la mínima por Nicaragua (35).

Mejorar la educación en Chile favorecería la participación de las personas en la esfera pública en calidad de ciudadanos informados y competentes, para así contar con una ciudadanía activa, participativa y eficaz. Es esencial un mayor conocimiento cívico de los procesos fundamentales de la democracia y una mejor comprensión del impacto político y económico de las acciones públicas. Tal argumento está respaldado por el débil coeficiente estimado entre el interés en la política y el apoyo a la democracia en Chile comparado con Argentina. En el caso argentino, a diferencia del caso chileno, hay una tendencia que indica que mientras mayor sea el interés por la política mayor es el apoyo a la democracia durante un año de crecimiento económico; durante crisis económicas tal relación se acentuó. En suma, se concluye que la cultura cívica y la educación son factores clave dentro del alto apoyo a la democracia en Argentina en comparación con el caso chileno.

presidente de Brasil?. Las respuestas positivas fueron sumadas y transformadas a una escala de 0 a 100. 


\section{El impacto de la orientación política}

Como se ha visto, las peculiaridades del cambio de modelo económico en los dos caso en estudio y el devenir histórico de la democracia precisan los contextos económicos, sociales y culturales en que se desarrollaron los hechos materia de análisis. Destacan las claras diferencias de cultura política que, entre otros, sugieren que han determinado los distintos niveles de apoyo a la democracia entre los pueblos chileno y argentino.

En esta perspectiva, se observa que en Chile el apoyo a la democracia está fuertemente condicionado, sobre todo por la orientación política de los encuestados. El coeficiente de regresión de la variable «escala política- derecha», en el caso chileno, es negativo y significativo respecto del apoyo a la democracia $^{10}$. Es decir, hay una tendencia que indica que los encuestados de derecha no apoyan la democracia en este caso. Ahora bien, desde una perspectiva comparada se destaca la pregunta ¿por qué esto ocurre en Chile pero no en Argentina?. Es decir, podría darse el caso de que los adherentes del partido opositor de turno apoyen menos la democracia, como sucede en Chile, pero no es así ${ }^{11}$.

En el caso argentino se distingue un evidente compromiso de la ciudadanía con la democracia, es decir, sobresale la vasta cultura política y cívica del país.

\footnotetext{
10 Ver anexo.

11 Desde 1990 al año 2010 la coalición de partidos de izquierda y centro denominada «concertación de partidos por la democracia» gobernó en Chile.
}

Esto se explica tanto en el alto nivel de apoyo a la democracia como respecto de los contextos del régimen político.

Ciertamente, a diferencia del caso argentino, el de Chile estuvo marcado por un fuerte régimen autoritario que no dio mucho espacio para que el pueblo, contrario al sistema, se manifestara y permaneció duramente reprimido. Carlos Huneeus reivindica esta realidad, y señala:

«Pinochet fue un dictador fuerte, en efecto, creo la DINA e impulsó la guerra contra el comunismo y el terrorismo, sin distanciarse de las acciones de violencia extrema producida por esta, ni siquiera cuando fue notoria su participación en el atentado que costó la vida a Orlando Letelier en Washington D.C. en 1976. Tampoco quitó el respaldo a los tecnócratas en los momentos difíciles de la crisis económica de 1982/83, ocasión en la cual aplicó una durísima coerción para frenar las protestas de oposición.»12

Desde otra perspectiva, el régimen militar chileno, a diferencia del argentino, llevó a cabo un agresivo programa de liberalización de la economía, persiguió una intensa integración comercial con el resto del mundo y una apertura a la inversión privada impulsando de esta manera el modelo económico de «economía de mercado».

12 Carlos Huneeus. Documento Electrónico [en línea]: Las consecuencias del caso Pinochet en la política chilena. Archivo Chile. Sin Fecha.

$<$ http://www.archivochile.com/Dictadura militar/pinochet/sobre/DMsobrepino80004.pdf> [Consulta: 01 Julio 2012]. 
Por lo anterior, tales diferencias en materia de represión y gobernanza económica de los regímenes autoritarios formaron parte de la cultura política de ambos pueblos. En Argentina la población expresó un mayor compromiso con la democracia, por lo que el factor político influyó mucho en la legitimidad del sistema; mientras en Chile la ciudadanía valoró sobre todo los aspectos económicos inherentes a la nueva institucionalidad, y soslayó sus fundamentos democráticos. Esto, evidentemente creó una fuerte polarización en el sistema político/social chileno, produciéndose no solo una enorme desigualdad de clases, sino, además, un marcado clivaje político.

\section{CONCLUSIÓN}

La investigación realizada puso énfasis en las diferencias en el apoyo a la democracia en Chile y Argentina y, considerando el mayor nivel en este último caso, se buscó encontrar las causas del fenómeno considerando que en las últimas décadas Chile ha logrado mayor éxito en términos políticos y económicos.

Para responder a esta interrogante, se realizó un modelo de regresión en perspectiva comparada entre los casos chileno y argentino durante un período de crecimiento económico y durante uno de crisis económica. El objetivo de tal técnica de análisis fue obtener aquellas variables independientes más significativas para cada caso en estudio puesto que se parte del supuesto de que el grado de influencia de estas respecto del apoyo a la democracia a causa de las crisis económicas puede variar.

Esta metodología estadística fue complementada mediante los antecedentes históricos respecto de los regímenes autoritarios de Argentina y Chile. En consecuencia, se investigó el origen de las diferencias en los niveles de apoyo a la democracia por medio de indagaciones en la cultura política.

Los resultados precisaron cuatro argumentos. Primero, respecto de la variable "percepción de la estabilidad de la economía» se concluyó que en Argentina esta es mayormente significativa al momento de apoyar la democracia que en el caso chileno. El manejo económico y los resultados generados por los regímenes militares y sistemas democráticos argentinos de las últimas décadas, marcados por una alta inflación y por un estancamiento de la economía, han hecho que esta variable sea altamente sensible. Segundo, en Argentina la confianza interpersonal es un factor significativo para el apoyo a la democracia, no así en el caso chileno. Esta variable está condicionada por la fuerte incertidumbre social, es decir, por los efectos de la corrupción y el desarrollo político, económico y social argentinos. Tercero, se concluye que la educación y el interés en la política son uno de los principales factores causales del alto nivel de apoyo a la democracia en Argentina en comparación con el caso chileno. En Argentina, el coeficiente estimado es positivo y consistente, por lo tanto, hay una tendencia que 
revela que los encuestados que han cursado la educación superior tienden a apoyar mayormente la democracia. Además, en este caso se distingue que también existe un coeficiente estimado significativo entre las personas a quienes les interesa la política y los que apoyan la democracia. Aquí se aprecia una consolidada cultura cívica y un amplio conocimiento político. No obstante, el caso chileno se caracteriza por una población con un mediocre conocimiento de los sucesos políticos, con ciudadanos poco informados y competentes, lo que evidentemente ha dañado la percepción de la democracia como el mejor sistema político. Cuarto, en Chile, a diferencia del caso argentino, se aprecia una fuerte polarización entre los adherentes de la izquierda y la derecha política, tendiendo estos últimos a una actitud más crítica hacia la democracia. Esto es una imagen del pasado y forma parte de la actitud que tuvieron los regímenes autoritarios. En Argentina, la población expresó un mayor compromiso con la democracia, en consecuencia, el factor político influyó en favor de la legitimidad democrática. En Chile, la ciudadanía valoró sobre todo los aspectos económicos dejando atrás los fundamentos democráticos. Esto desarrolló una fuerte polarización en el sistema político/social chileno, desencadenándose una fuerte desigualdad de clases y un marcado clivaje político.

En suma, si consideramos, comparativamente, los traumas políticos de Argentina y Chile podemos concluir que la sociedad argentina fue más proclive a la búsqueda de unidad para hacer frente al régimen autoritario, en cambio la sociedad chilena fue mucho más reprimida por el régimen de Pinochet. Por otro lado, el régimen militar chileno fue exitoso respecto de la gobernabilidad económica, lo que se compensó con un fuerte crecimiento económico. En cambio el gobierno militar argentino fracasó en términos económicos generándose el proceso de transición democrática dentro de una profunda crisis económica. Tales hechos fueron trascendentes para la actual percepción de la democracia $y$, en consecuencia, en las diferencias respecto del impacto de las variables más significativas al momento de considerar la democracia como el mejor sistema político. 


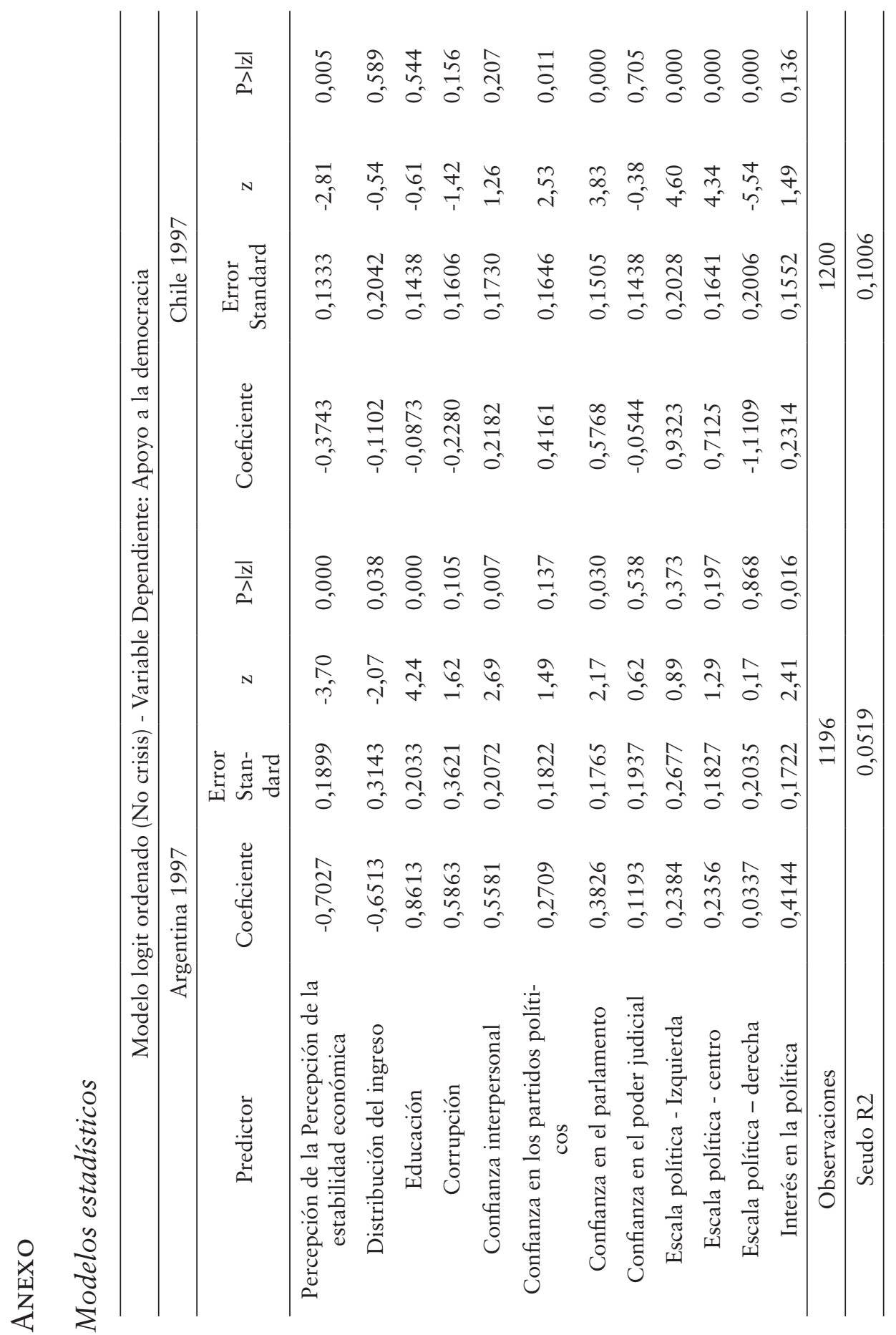


Estudios Internacionales 173 (2012) • Universidad de Chile

\begin{tabular}{|c|c|c|}
\hline 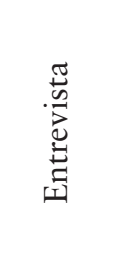 & 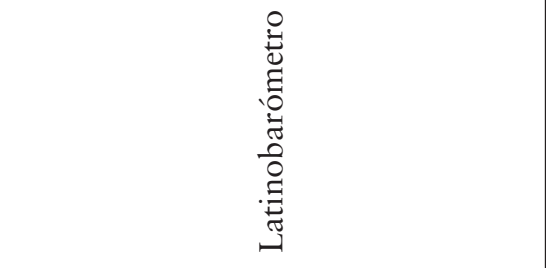 & 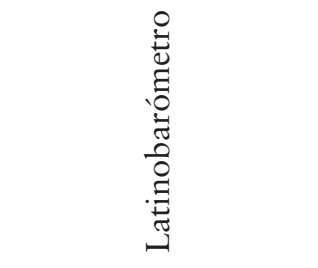 \\
\hline 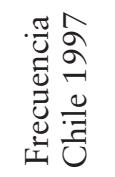 & 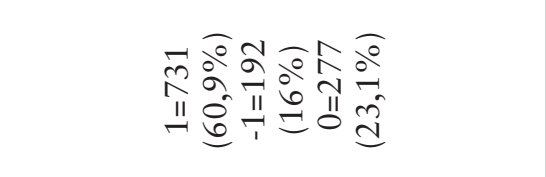 & 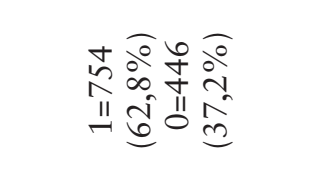 \\
\hline 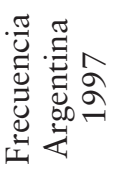 & 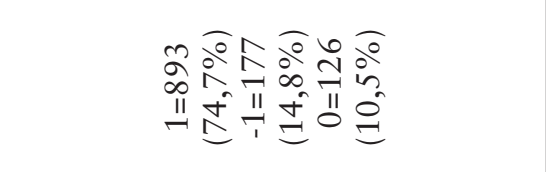 & 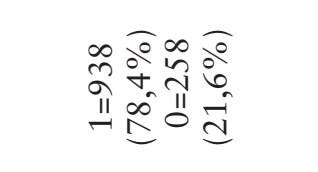 \\
\hline 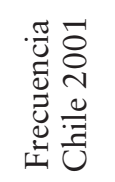 & 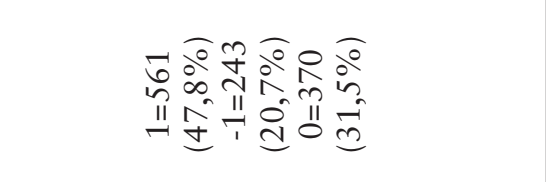 & 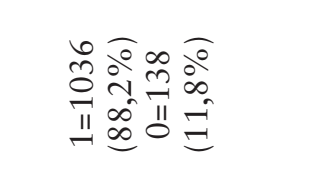 \\
\hline 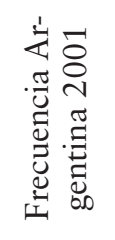 & 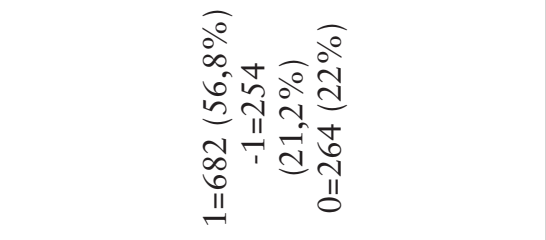 & 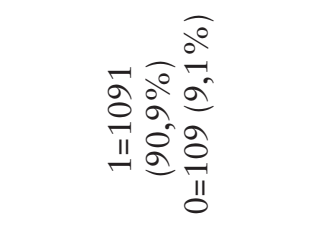 \\
\hline $\begin{array}{l}0 \\
\stackrel{60}{E} \\
\underset{\Xi}{\Xi}\end{array}$ & 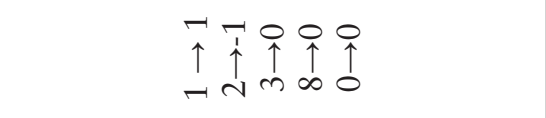 & 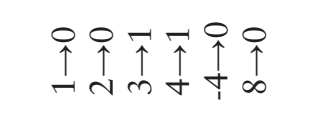 \\
\hline 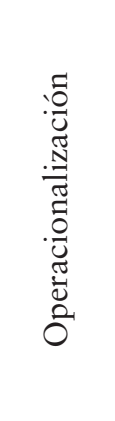 & 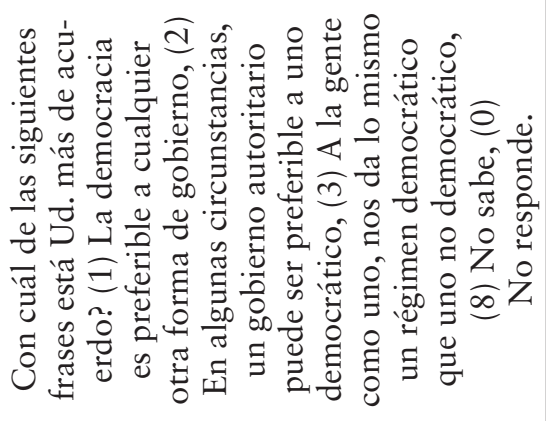 & 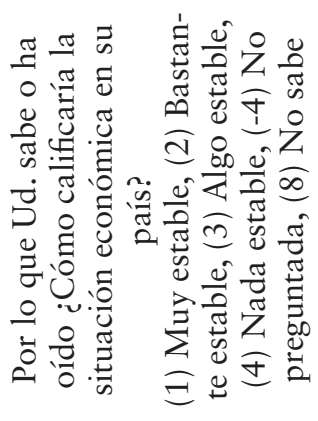 \\
\hline$\frac{\frac{\pi}{0}}{\frac{\pi}{3}}$ & 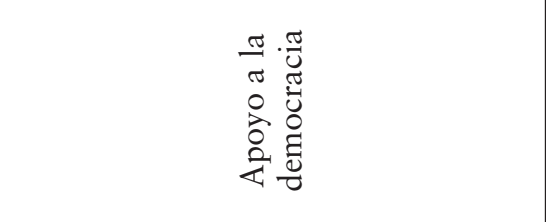 & 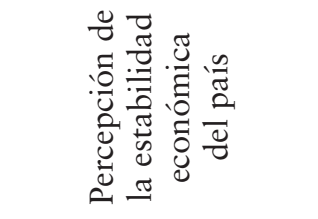 \\
\hline
\end{tabular}


Pedro Aravena Lavín • Dos hermanos muy distintos

\begin{tabular}{|c|c|}
\hline 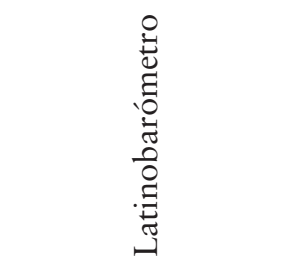 & 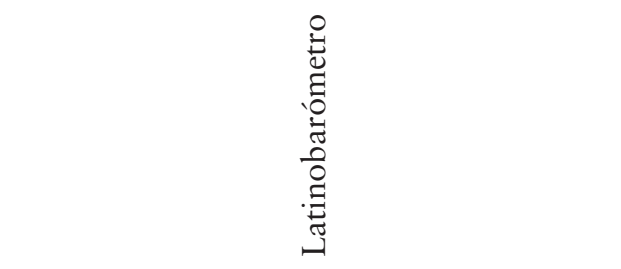 \\
\hline 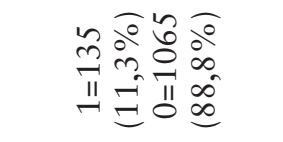 & 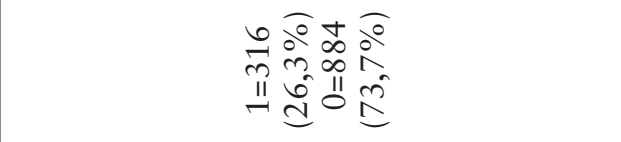 \\
\hline 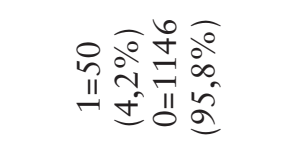 & 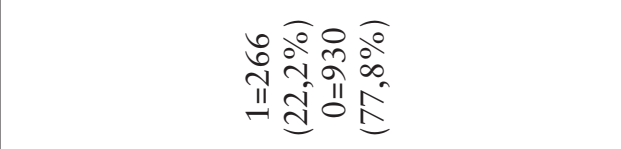 \\
\hline 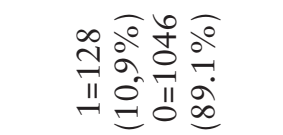 & 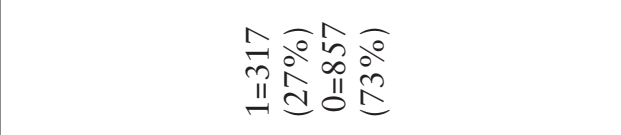 \\
\hline 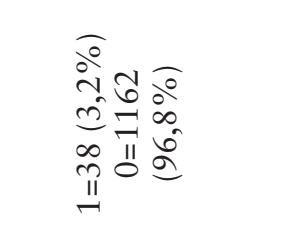 & 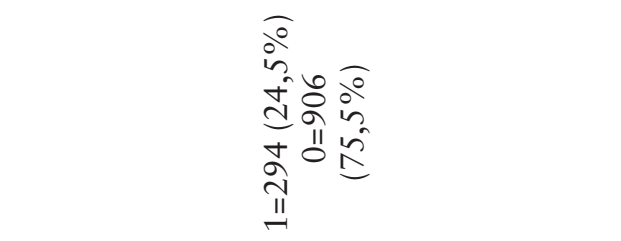 \\
\hline 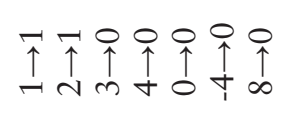 & 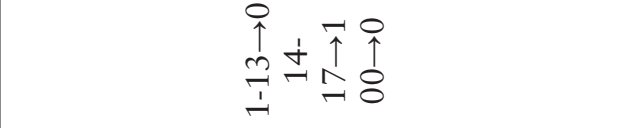 \\
\hline 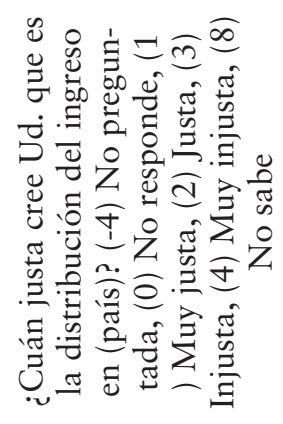 & 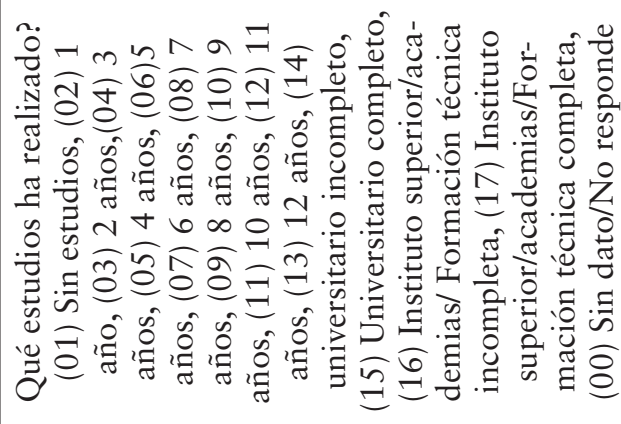 \\
\hline 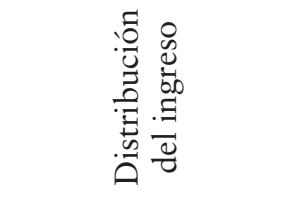 & 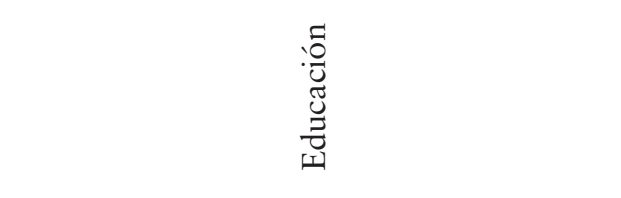 \\
\hline
\end{tabular}


Estudios Internacionales 173 (2012) • Universidad de Chile

\begin{tabular}{|c|c|}
\hline 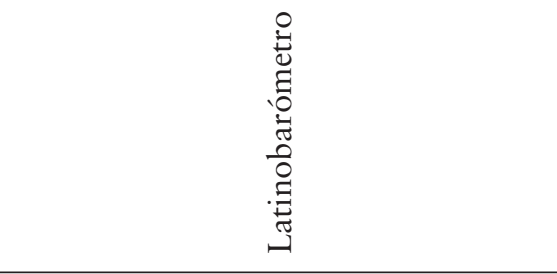 & 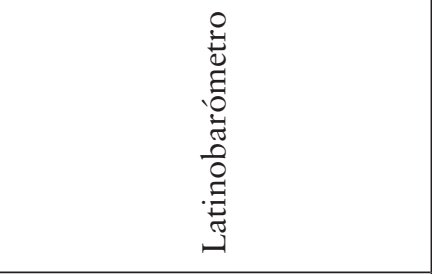 \\
\hline 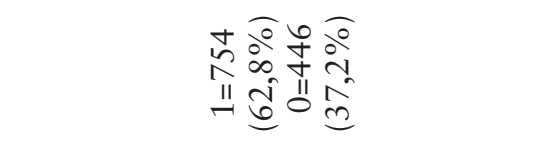 & 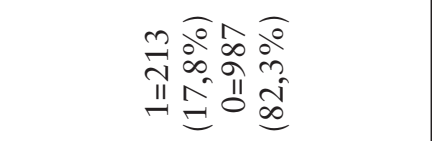 \\
\hline 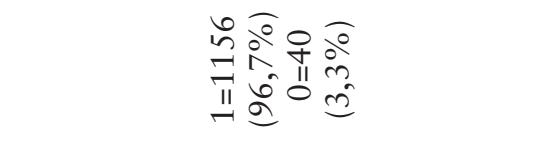 & 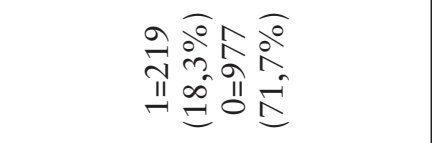 \\
\hline 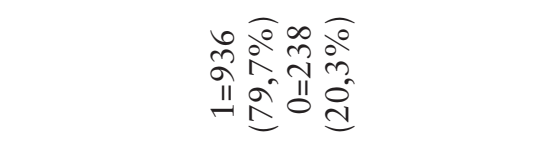 & 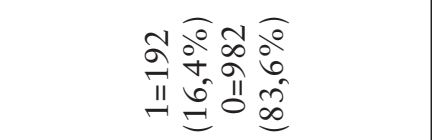 \\
\hline 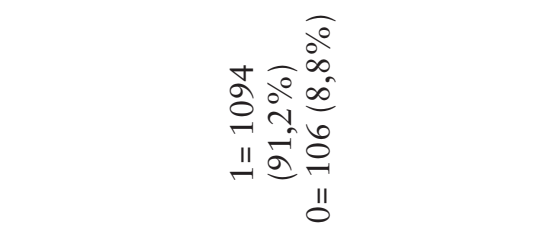 & 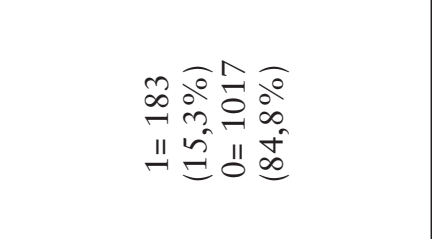 \\
\hline 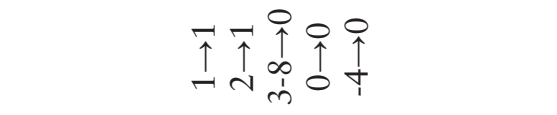 & 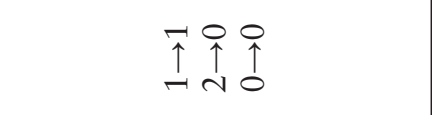 \\
\hline 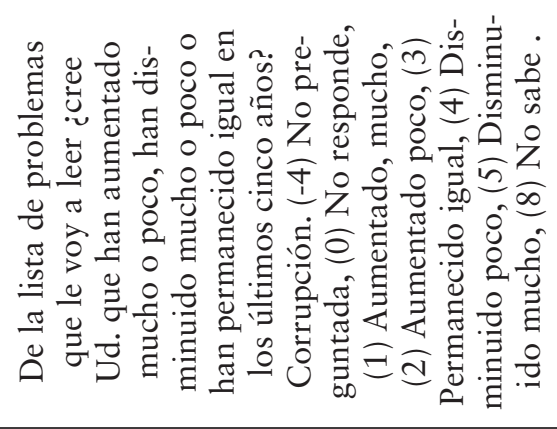 & 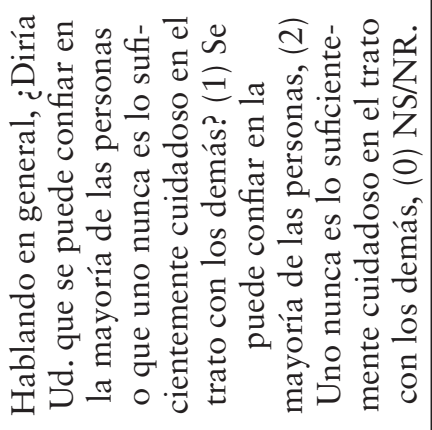 \\
\hline 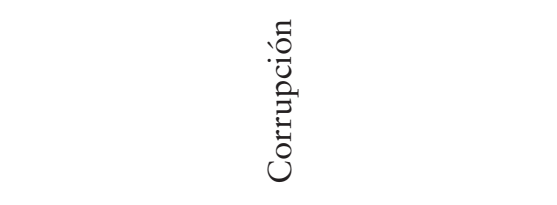 & 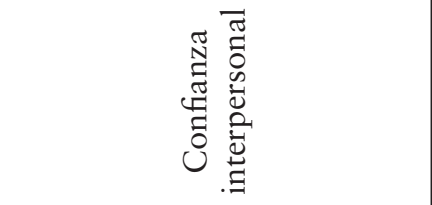 \\
\hline
\end{tabular}


Pedro Aravena Lavín • Dos hermanos muy distintos

\begin{tabular}{|c|c|c|}
\hline 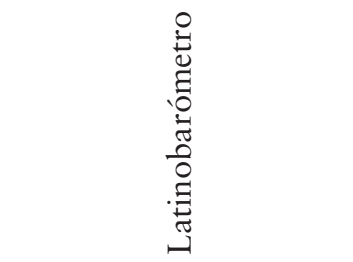 & 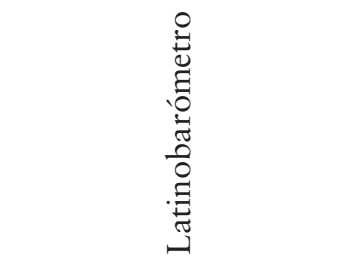 & 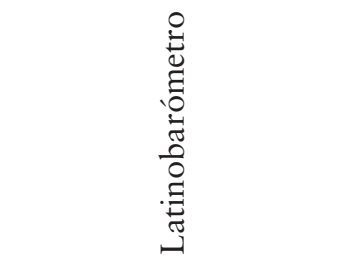 \\
\hline 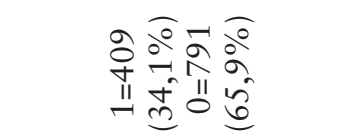 & 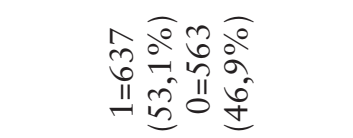 & 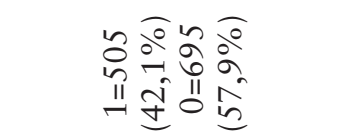 \\
\hline 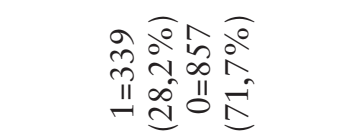 & 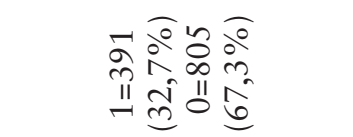 & 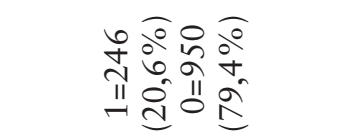 \\
\hline 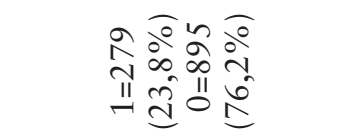 & 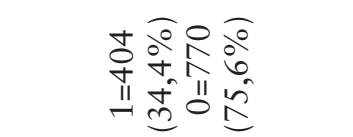 & 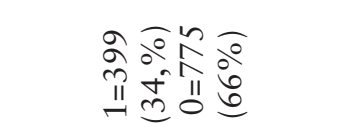 \\
\hline 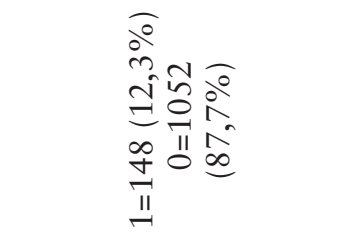 & 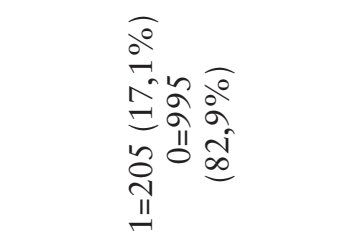 & 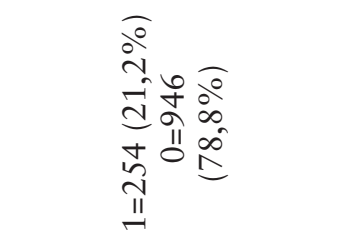 \\
\hline 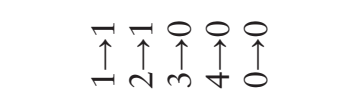 & 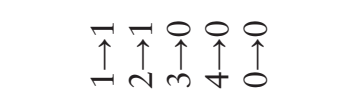 & 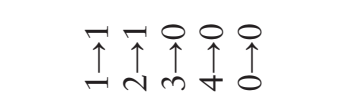 \\
\hline 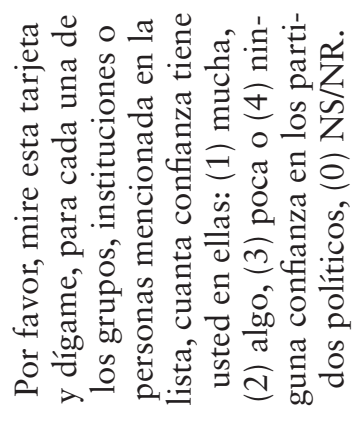 & 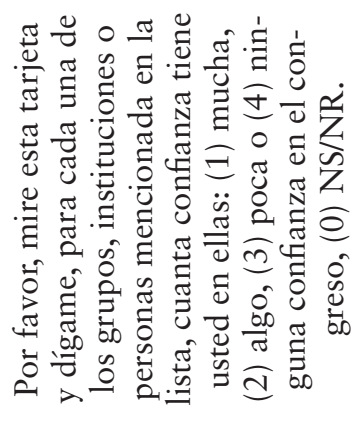 & 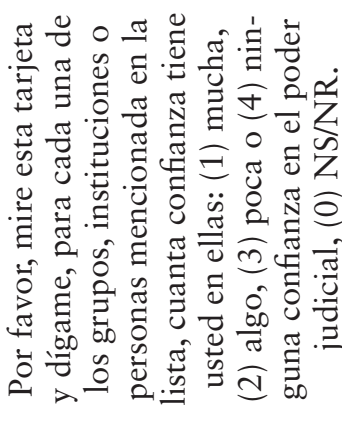 \\
\hline 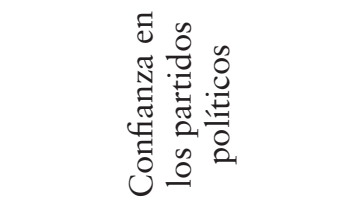 & 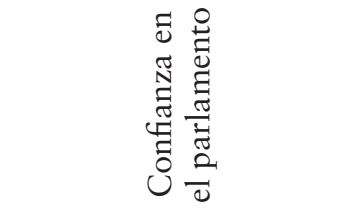 & 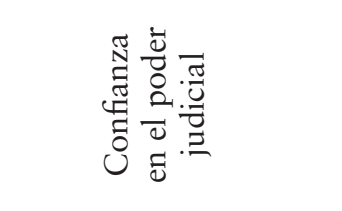 \\
\hline
\end{tabular}




\begin{tabular}{|c|c|c|c|}
\hline 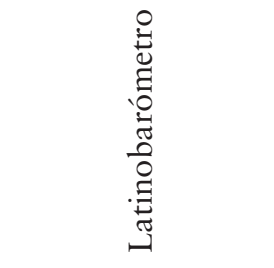 & 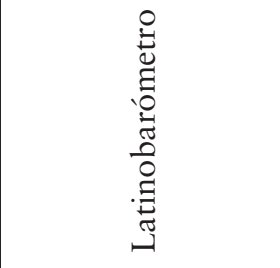 & 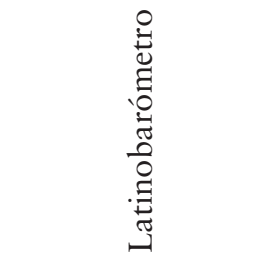 & 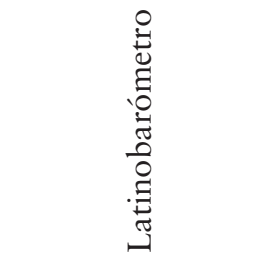 \\
\hline 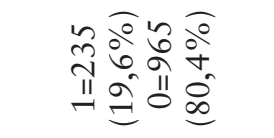 & 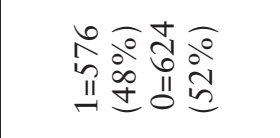 & 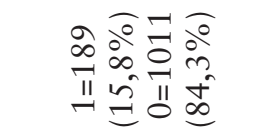 & 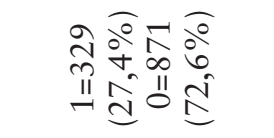 \\
\hline 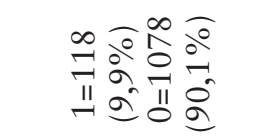 & 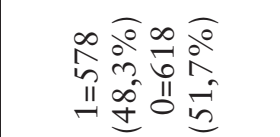 & 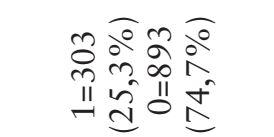 & 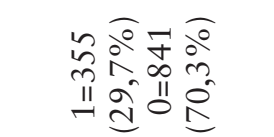 \\
\hline 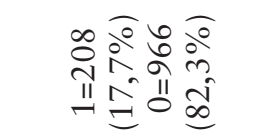 & 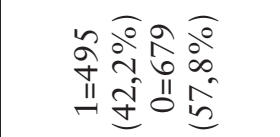 & 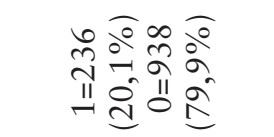 & 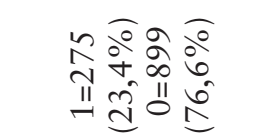 \\
\hline 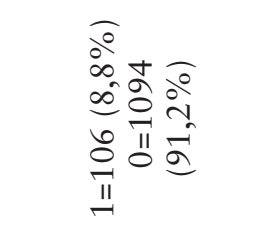 & 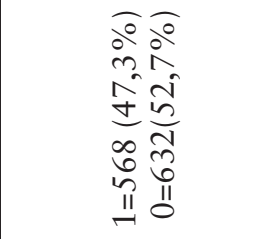 & 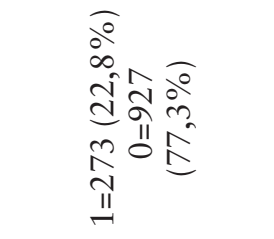 & 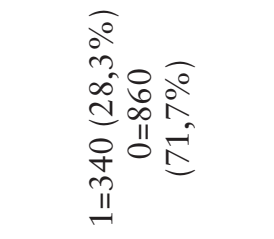 \\
\hline 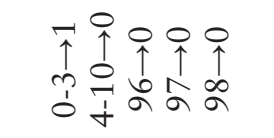 & 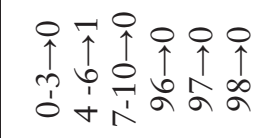 & 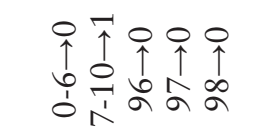 & 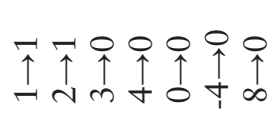 \\
\hline 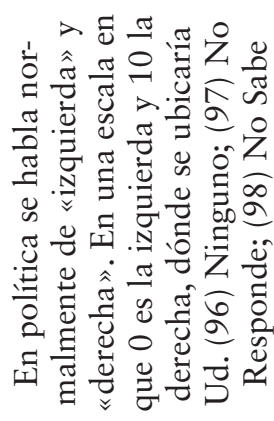 & 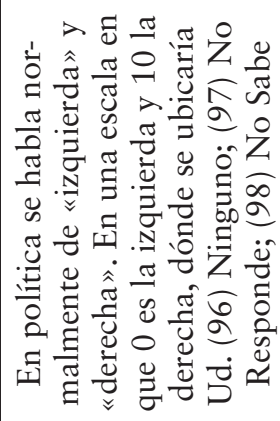 & 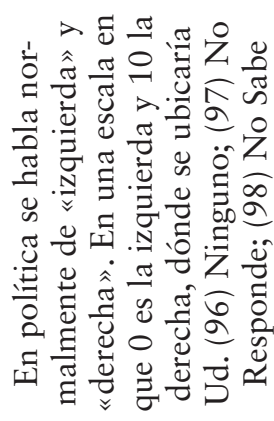 & 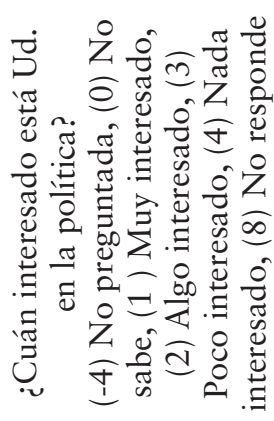 \\
\hline 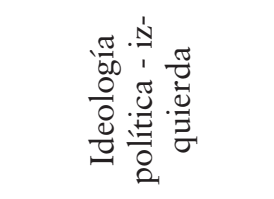 & 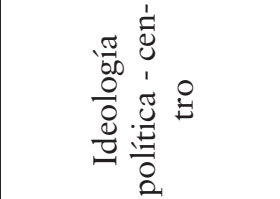 & 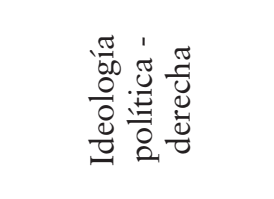 & 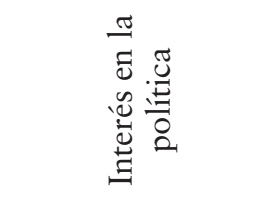 \\
\hline
\end{tabular}


Pedro Aravena Lavín • Dos hermanos muy distintos

\section{BIBLIOGRAFÍA}

Almond, Gabriel y Sidney Verba (1965), The civic culture. Political attitudes and democracy in five nations, Princeton: Princeton Univesity Press.

Abós, Alvaro (1984), Las organizaciones sindicales y el poder militar (1976-1983), Buenos Aires: Centro Editor de América Latina.

Berggren, Heidi, Gregory Fugate y Dennis Still (2004), «Satisfied? Institutional Determinants of citizen Evaluations of Democracy», Politics \& Policy, Vol. 32, N¹.

Burt, Ronald (2000), «The Network Structure of Social Capital», en Robert Sutton y Barry Staw (eds), Research in Organizational Behavior, Vol. 22, Greenwich: Gray Press.

Caïs, Jordi (1997), Metodología de Análisis Comparativo, Madrid: Editorial Centro de Investigaciones Metodológicas.

Carlin, Ryan E. (2006), "The Socioeconomic Roots of Support for Democracy and The Quality of Democracy in Latin America», Revista Ciencia Política de la Pontificia Universidad Católica de Chile, Volumen 26, № 1 .

Comisión Económica para América Latina y el Caribe (2003), Anuario Estadístico de América Latina y el Caribe.

Comisión Económica para América Latina y el Caribe (2004), Anuario Estadístico de América Latina y el Caribe.

Converse, Philip (1969), "Of time and partisan stability", Comparative Political Studies, Volumen 2, N² 2 .

Corporación Latinobarómetro (2003), Informe de prensa Latinobarómetro.

Cutright, Phillips y James Wiley (1969), «Modernization and political representation: 1927-1966", Studies in Comparative International Development, Volumen. 5.

Deutsch, Karl (1961), «Social Mobilization and Political Development", American Political Science Review, Volumen 60, N³.

Diamond, Larry (1992), «Reconsideración del nexo entre desarrollo económico y democracia", American Behavioral Scientist, Volumen $35, \mathrm{~N}^{\circ} 45$.
French-Davis, Ricardo y Raúl Labán (1996), «Macroeconomic Performance and Achievements in Chile», en Crisóstomo Pizarro, Dagmar Raczynski y Joaquín Vial (eds), Social and Economic Policies in Chile's Transition to Democracy, Santiago: CIEPLAN UNICEP.

Fuchs, Dieter, Giovanna Guidorossi y Palle Svensson (1995), «Support for the democratic system», en: Hans Dieter Klingemann y Dieter Fuchs (eds.), Citizens and the State, Oxford: Oxford University Press.

Gasiorowski, Mark (1988), «Economic Dependence and Political Democracy: A Cross-national Study», Comparative Political Studies, Volumen 20, Nº4.

Gasiorowski, Mark (1995), «Economic Crisis and Political Regime Change: An Event History Analysis", American Political Science Review, Volumen 89, Nº4.

González, Sonia (2006), «Desconfianza política: el colapso del sistema de partidos en Venezuela», en Romer Cornejo (ed), En los intersticios de la democracia y el autoritarismo. Algunos casos de Asia, África y América, Buenos Aires, Consejo Latinoamericano de Ciencias Sociales.

Graham, Carol y Sandit Sukhtankar (2004), «Does Economic Crisis Reduce Support for Markets and Democracy in Latin America?", Journal of Latin American Studies, Vol. 36, N²2.

Hamilton, Lawrence C. (2006), Statistics with Stata updated for version 9, Belmont, CA: Brooks/Cole-Thomson Learning.

Huneeus, Carlos y Luis Maldonado (2003), «Demócratas y nostálgicos del antiguo régimen. Los apoyos a la democracia en Chile», Revista Española de Investigaciones Sociológicas (REIS), No 103.

Huneeus. Carlos. Documento Electrónico [en línea]: Las consecuencias del caso Pinochet en la política chilena. Archivo Chile. Sin Fecha. <http://www.archivochile.com/Dictadura_militar/pinochet/sobre/DMsobrepino80004.pdf> [Consulta: 01 Julio 2012].

Huntington, Samuel (1984), "Will more countries become democratic?", Political Science Quarterly, Volumen 99, N². 
Huntington, Samuel (1991), The third wave: democratization in the late twentieth century, Norman: University of Oklahoma Press.

Inglehart, Ronald (1991), El cambio cultural en las sociedades industriales avanzadas, Madrid: Siglo XXI.

Jong-Sung You (2005), "Corruption and Inequality as Correlates of Social Trust: Fairness Matters More Than Similarity», The Hauser Center for Nonprofit Organizations and The John F. Kennedy School of Government Harvard University, Working Paper No.29

Klingemann, Hans-Dieter y Dieter Fuchs (1998), "Citizens and the state: a relationship transformed», en H.D. Klingemann y D. Fuchs (eds.), Beliefs in government, Volumen 1, Nueva York: Oxford University Press..

Knutson, Jeanne Nickell (1973), Handbook of political psychology, San Francisco: Jossey-Bass Publishers.

Lerner, Daniel (1958), The Passing of Traditional Society, Glencoe, IL: Free Press.

Levi, Margaret (1998), "A State of Trust», en V. Braithwaite y M. Levi (eds), Trust and Governance, Nueva York: Russell Sage Foundation.

Lijphart, Arend (1977), Democracy in Plural Societies: A Comparative Exploration, New Haven: Yale University Press.

Linz, Juan y Arturo Valenzuela (1994), The Crisis of Presidential Democracy: The Latin American Evidence, Baltimore: The Johns Hopkins University Press.

Lipset, Seymour (1959), «Some social requisites of democracy: Economic development and political legitimacy», American Political Review, Volumen 53, Nº1.

Lipset, Seymour, Martin Seong, KyoungRyung y John Torres (1993), "A comparative analysis of the social requisites of democracy», International Social Science Journal, Volumen 136, Nº1.

Mainwaring, Scott (1993), "Presidentialism, Multipartism, and Democracy: The Difficult Combination", Comparative Political Studies, Volumen 26, N².
O`Donnell, Guillermo (1973), Modernization and Bureaucratic-Authoritarianism, Berkeley: University of California, Institute for International Studies.

Ocampo, José Antonio (2003), «Educación: clave para el fortalecimiento de la democracia», en: Ricardo Díez Hochleitner (ed), Aprender para el futuro: educación para la convivencia democrática, Madrid: Santillana.

Páez, Darío y M. Campos (2004), «Cultura, evitación de la incertidumbre y confianza interpersonal», en D. Páez, I. Fernández, S. Ubillos y E. Zubieta (eds), Psicología social, cultura y educación, Madrid: Pearson/Prentice-Hall.

Petermann, Franz (1999), Psicología de la confianza, Barcelona: Herder

Putnam, Robert (1994), Comunidade e Democracia: A Experiência da Itália Moderna, Rio de Janeiro: Fundação Getúlio Vargas.

Putnam, Robert (1993), Making Democracy Work: Civic Traditions in Modern Italy, Princeton: Princeton University Press.

Putnam, Robert (1995), «Tuning In, Tuning Out: The Strange Disappearance of Social Capital in America", PS Political Science \& Politics, Volumen 28, No 4.

Sartori, Giovanni (1994), "Comparación y método comparativo", Sartori, G. y Morlino, L. (eds), La comparación en las ciencias sociales, Madrid: Alianza.

Sartori, Giovanni (1999), «Democracia y sociedad de la información», Claves de razón práctica, Volumen 97.

Sepúlveda, Luis (2006), Quién nos salva de los jueces chilenos, en: Le Monde Diplomatique, $\mathrm{N}^{\circ} 284$.

Swanson, David (1995), «El campo de comunicación política. La democracia centrada en los medios», en: Alejandro MuñozAlonso y Juan Ignacio Rospir (eds), Comunicación Política. Madrid: Universitas.

Weil, Frederick (2000), The effects of difusión, nostalgia, and performance on democratic legitimation in unified germany: An analisis using structural equations models. Universidad Estatal de Louisiana, en: $<$ http://www.lsu.edu/faculty/fweil/WeilFrankfurt-Oder.pdf> 